\title{
Rapid Disappearance of Testicular Plasmacytoma after Treatment with Lenalidomide plus Dexamethasone
}

\author{
Masao Hagihara $^{{ }^{*}}$, Morihiro Inoue ${ }^{1}$, Jian Hua ${ }^{1}$, Nobuyasu Iwaki ${ }^{1}$, Kosuke Yoshioka ${ }^{2}$, \\ Takeshi Kobayashi ${ }^{2}$ \\ ${ }^{1}$ Department of Hematology, Eiju General Hospital, Tokyo, Japan; ${ }^{2}$ Hematology Division, Tokyo Metropolitan Cancer and Infectious \\ Diseases Center, Komagome Hospital, Tokyo, Japan. \\ Email: "hagihara@eijuhp.com
}

Received June $2^{\text {nd }}, 2012$; revised July $6^{\text {th }}, 2012$; accepted July $18^{\text {th }}, 2012$

\begin{abstract}
We describe a rare case of testicular plasmacytoma first manifesting as a relapse. The patient was initially diagnosed with IgG- $\lambda$-type multiple myeloma and treated with melphalan and prednisolone plus bortezomib, achieving a complete remission. Four months later, his left scrotum began to swell and pathological investigation of a needle biopsy specimen revealed proliferation of plasma cells expressing IgG- $\lambda$, confirming myeloma recurrence. However, bone marrow aspiration samples showed no significant increase in myeloma cells and there was no skewed deviation of the $\kappa / \lambda$ ratio on flow-cytometric analysis. The extramedullary tumors disappeared completely soon after treatment with lenalidomide plus dexamethasone, and the patient was judged to be in very good partial remission based on negative M-protein results by serum immunoelectrophoresis. This is the first report, to our knowledge, describing complete disappearance of a testicular plasmacytoma after treatment with lenalidomide as the key-drug.
\end{abstract}

Keywords: Plasmacytoma; Testis; Lenalidomide

\section{Introduction}

Extramedullary plasmacytoma (EMP) is a plasma cell neoplasm that occurs as a solitary lesion or develops simultaneously or secondarily to multiple myeloma (MM). EMP can involve a wide variety of anatomical sites, but approximately $85 \%$ of all cases have disease in the head and neck region [1]. Testicular plasmacytoma is extremely uncommon and estimated to account for $0.03 \%$ $0.1 \%$ of all testicular malignancies or around $2 \%$ of all plasma cell neoplasms [2-5]. In previous reports, the majority of testicular plasmacytoma cases had been diagnosed based on local manifestation of systemic plasma cell disorders rather than as having a solitary EMP [2,6-9].

Herein, we present a rare case in which testicular involvement without bone marrow invasion was observed 4 months after the first complete remission of MM had been achieved using a regimen that included bortezomib. Furthermore, the extramedullary tumor disappeared completely after treatment with another novel anti-myeloma reagent, lenalidomide.

\section{Case Report}

A 78-year-old man was admitted to our hospital in March

*Corresponding author.
2011. Two years before (in 2009), the patient had complained of pain in multiple bones, which led to a diagnosis of IgG- $\lambda$-type MM, Durie-Salmon stage II, with multiple bone fractures (ribs, thoracic and lumbar vertebrae), elevated serum IgG $(6075 \mathrm{mg} / \mathrm{dL})$ and proliferation of plasma cells ( $18 \%$ of whole nucleated cells) in bone marrow. After receiving 10 cycles of melphalan and prednisolone plus bortezomib (MPV) treatment, he had achieved a complete remission in October 2010. In February 2011, swelling in his left scrotum manifested. Although there were no significant changes in laboratory data, his serum IgG level was slightly increased (1872 $\mathrm{mg} / \mathrm{dL}$ ) and a monoclonal band of IgG- $\lambda$ was identified by immunoelectrophoresis. At that time, a needle biopsy of the left scrotum was performed, and the proliferation of plasma cells was revealed by pathological investigation. As shown in Figure 1, the plasma cells expressed the IgG- $\lambda$ light chain and CD138 when examined immunohistochemically, confirming the tumor to be a myeloma recurrence.

On admission, magnetic resonance imaging (MRI) showed an enlarged mass in the left scrotum and chest computed tomography (CT) demonstrated a tumor in the right thoracic pleura (Figures 2(a) and (c)). However, bone marrow aspiration samples showed no significant 


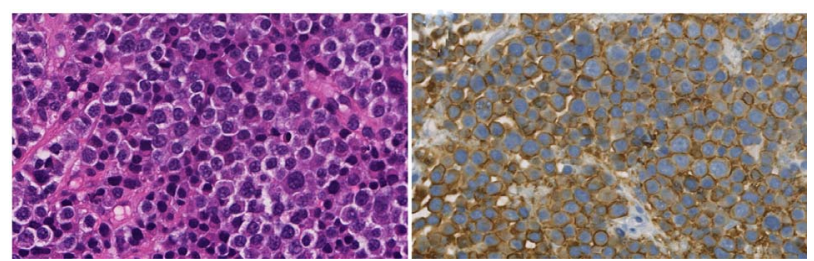

(a)

(b)

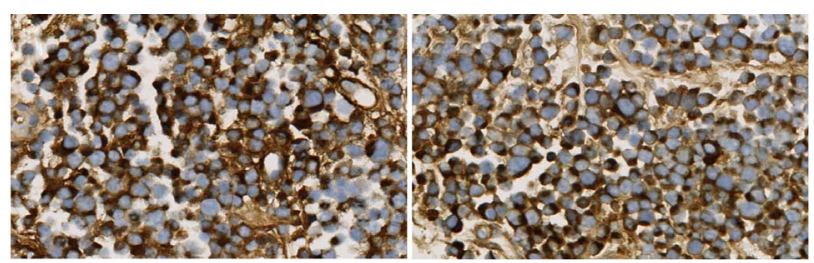

(c)

(d)

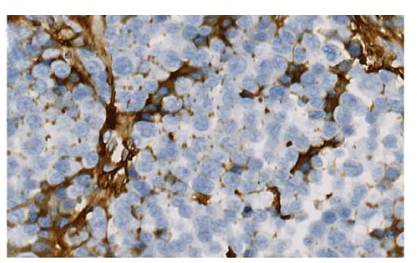

(e)

Figure 1. Proliferation of plasma cells in testicular tissue. The sections were stained with (a) Hematoxylin and eosin; (b) Anti-CD38; (c) Anti-IgG; (d) Anti- $\lambda$; (e) Anti- $\kappa$; Original magnification $\times \mathbf{4 0}$.

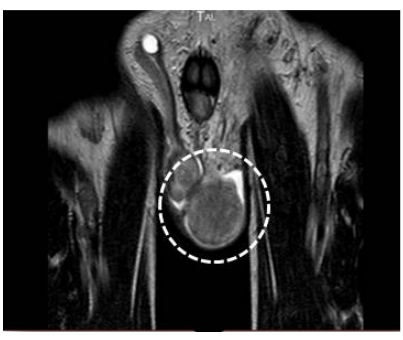

(a)

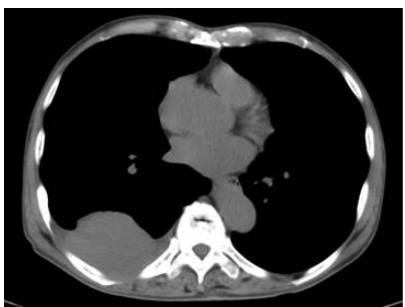

(c)

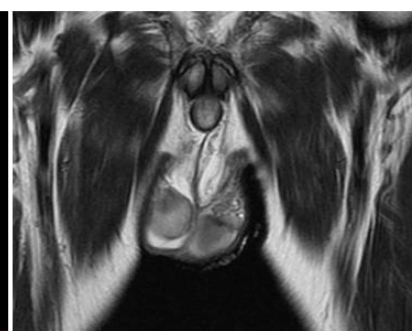

(b)

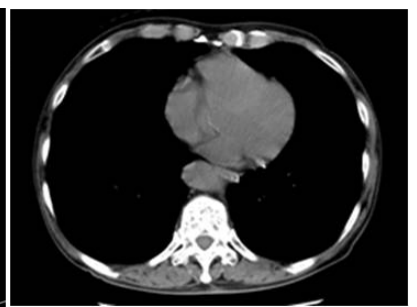

(d)
Figure 2. MRI and CT findings at disease onset ((a) and (c), respectively) and after treatment ((b) and (d), respectively). The masses in the left scrotum and right thoracic pleura disappeared completely after Ld treatment.

increase of myeloma cells, and flow-cytometric analysis did not reveal a skewed deviation of the $\kappa / \lambda$ ratio. The patient was treated with lenalidomide (L: $25 \mathrm{mg} /$ day $\times 21$ days) plus dexamethasone (d: $20 \mathrm{mg}$ on days 1,8 , and 15). After 3 cycles of this treatment, total IgG decreased to within normal range (less than half of the initial level) and the left testicular and right thoracic tumors both disappeared completely (Figures 2(b) and (d)). As of October 2011, the patient has continued to receive monthly Ld treatments and is thought to have entered a period of very good partial remission (VGPR) based on negative M-protein results obtained using serum immunoelectrophoresis. During these treatments, a moderate skin eruption transiently appeared but resolved rapidly with shortterm application of an anti-allergic drug. The only other adverse reaction was grade 3 neutropenia, From December 2011 through April 2012, the patient has received maintenance therapy with low-dose lenalidomide therapy (10 mg/dL $\times 3$ weeks per every 28-day cycle) and has remained in VGPR.

\section{Discussion}

EMP is a rare tumor that can appear at various anatomical sites but is most frequently found in the respiratory system or gastrointestinal tract as well as the lymph nodes or skin [5]. Although testicular plasmacytoma is a relatively rare disorder, more than 50 cases have been reported since its first description by Ulrich $[10,11]$. Anghel et al. reviewed 51 cases in 2002. According to their report, the median age of patients was 51 years and higher than that of testicular cancer [12]. Moreover, they mentioned that the occurrence of a solitary testicular plasmacytoma without MM was unusual [6]. In fact, 34 of the 51 cases had previous or simultaneous MM and/or EMP. Twenty of these 34 cases had a fatal clinical course with progressive disease with only 4 patients surviving. In one of Anghel's cases, the plasmacytoma showed a tendency to spread not only to the testis but also to other sites including multiple bones, the lung, skin, and pancreas [6].

EMP is widely regarded as being radiosensitive and can be successfully controlled with local radiotherapy [13]. For testicular EMP, an orchiectomy followed by chemotherapy or radiotherapy is considered to be a therapeutic option [14]. Turk et al. recently reported a case of MM that presented with a testicular plasmacytoma and multiple bone lesions [1]. The patient received chemotherapy consisting of melphalan and prednisolone and palliative radiotherapy after orchiectomy. In our case, as the patient had an extramedullary tumor not only in the testis but also in the thoracic wall, chemotherapy using lenalidomide plus low dose dexamethasone was selected as a salvage regimen without orchiectomy.

Since the first description by Krauth et al., bortezomib has been recognized as an effective agent for EMP treatment $[15,16]$. However, thalidomide lacks efficacy against soft-tissue plasmacytoma [17]. Lenalidomide, an analogue of thalidomide, has much more potent antitumor activity [18] and the response is unaffected by 
previous bortezomib treatment [19,20]. Rosenberg et al. presented a case of testicular plasmacytoma with previous MM in which regression of the mass was achieved using a combination of bortezomib and lenalidomide [21]. Furthermore, Carovo-Villas et al. recently reported that lenalidomide in combination with dexamethasone was effective against extramedullary plasmacytoma in patients with relapsed or refractory MM [22]. For their 18 reported cases, the overall response was $61 \%$, including a complete disappearance in $44 \%$ of these cases. It was assumed that lenalidomide could have direct anti-proliferative mechanisms on myeloma cells irrespective of its existence in the bone marrow stroma or other tissue microenvironments [23]. Angiogenesis is promoted in plasmacytoma tissue, such that lenalidomide might exhibit anti-tumor activity especially through its anti-angiogenic effects [24]. Adams et al. reported that bortezomib did not penetrate into testicular tissue [25]. It might be the reason why plasmacytoma appeared especially in testis. Our experience might indicate that lenalidomide could possibly be distributed in testis.

Carovo-Villas et al. noted that 3 of 11 patients relapsed and new strategies were thus necessary to overcome treatment resistance of the disease [22]. Recently, abundant encouraging data have been accumulated regarding the clinical significance of maintenance therapy using lenalidomide [26]. Therefore, we are still now giving this patient low-dose lenalidomide alone, as maintenance therapy, even though attained VGPR.

In conclusion, we demonstrated an excellent clinical effect of lenalidomide on a rare type of testicular plasmacytoma in a patient with relapse after administration of bortezomib, the widely accepted first choice for the EMP treatment.

\section{REFERENCES}

[1] H. M. Turk, S. Komurcu, A. Ozet, O. Kuzhan and O. Gunhan, "An Unusual Presentation of Extramedullary Plasmacytoma in Testis and Review of the Literature," Medical Oncology, Vol. 27, No. 4, 2010, pp. 1378-1380. doi:10.1007/s12032-009-9390-X

[2] H. S. Levin and F. K. Mostofi, "Symptomatic Plasmacytoma of the Testis," Cancer, Vol. 25, No. 5, 1970, pp. 1193-1203.

doi:10.1002/1097-0142(197005)25:5<1193::AID-CNCR2 820250527>3.0.CO;2-6

[3] G. Chica, D. E. Johnson and A. G. Ayala, "Plasmacytoma of Testis Presenting as Primary Testicular Tumor," Urology, Vol. 11, No. 1, 1978, pp. 90-92. doi:10.1016/0090-4295(78)90213-3

[4] N. F. Gowing, "Malignant Lymphoma of the Testis," British Journal of Urology, Vol. 36, 1964, pp. 85-94.

[5] D. W. Hayes, W. A. Bennett and F. J. Heck, "Extramedullary Lesions in Multiple Myeloma: Review of Literature and Pathologic Studies," AMA Archives of Pathology,
Vol. 53, No. 3, 1952, pp. 262-272.

[6] G. Anghel, N. Petti, D. Remotti, C. Ruscio, F. Blandino and I. Majolino, "Testicular Plasmacytoma: Report of a Case and Review of the Literature," American Journal of Hematology, Vol. 71, No. 2, 2002, pp. 98-104. doi:10.1002/ajh.10174

[7] A. M. Avitable, T. S. Gansler, J. E. Tomaszewski, P. Hanno and M. I. Goldwein, "Testicular Plasmacytoma," Urology, Vol. 34, No. 1, 1989, pp. 51-54. doi:10.1016/0090-4295(89)90159-3

[8] P. I. Oppenheim, S. Cohen and K. H. Anders, "Testicular Plasmacytoma. A Case Report with Immunohistochemical Studies and Literature Review," Archives of Pathology \& Laboratory Medicine, Vol. 115, No. 6, 1991, pp. 629-632.

[9] M. Castagna, P. Gaeta, M. Cecchi, G. L. Pagni and R. Pingitore, "Bilateral Synchronous Testicular Involvement in Multiple Myeloma. Case Report and Review of the Literature,” Tumori, Vol. 83, No. 4, 1997, pp. 768-771.

[10] J. A. Ferry, R. H. Young and R. E. Scully, "Testicular and Epididymal Plasmacytoma: A Report of 7 Cases, Includeing Three That Were the Initial Manifestation of Plasma Cell Myeloma," The American Journal of Surgical Pathology, Vol. 21, No. 5, 1997, pp. 590-598. doi:10.1097/00000478-199705000-00013

[11] H. Ulrich, "Multiple Myeloma," Archives of Internal Medicine, Vol. 64, No. 5, 1939, pp. 994-1016. doi:10.1001/archinte.1939.00190050100008

[12] S. D. Fossa, M. Cvancarova, L. Chen, A. L. Allan, J. Oldenburg, D. R. Peterson and L. B. Travis, “Adverse Prognostic Factors for Testicular Cancer-Specific Survival: A Population-Based Study of 27,948 Patients," Journal of Clinical Oncology, Vol. 26, No. 6, 2011, pp. 963-970. doi:10.1200/JCO.2010.32.3204

[13] N. A. Mayr, B. C. Wen, D. H. Hussey, C. P. Burns, J. J. Staples, J. F. Doornbos and A. P. Vigliotti, "The Role of Radiation Therapy in the Treatment of Solitary Plasmacytomas," Radiotherapy and Oncology: Journal of the European Society for Therapeutic Radiology and Oncology, Vol. 17, No. 4, 1990, pp. 293-303. doi:10.1016/0167-8140(90)90003-F

[14] M. Alvarez-Mugica, A. J. Monzon, V. B. Vazquez, C. A. Andrea, J. M. F. Gomez, R. C. G. Alvarez and F. J. R. Sejas, "Secondary Testicular Plasmocytoma," Archivos Espanoles de Urologia, Vol. 60, No. 1, 2007, pp. 99-102.

[15] M. T. Krauth, A. Bankier, P. Valent, P. Kalhs and J. Drach, "Sustained Remission Including Marked Regression of a Paravertebral Plasmacytoma in a Patient with Heavily Pretreated, Relapsed Multiple Myeloma after Treatment with Bortezomib," Leukemia Research, Vol. 29, No. 12, 2005, pp. 1473-1477. doi:10.1016/j.leukres.2005.05.003

[16] R. Laura, M. T. Cibeira, C. Uriburu, S. Yantorno, O. Salamero, J. Blade and E. Montserrat, "Bortezomib: An Effective Agent in Extramedullary Disease in Multiple Myeloma,” European Journal of Haematology, Vol. 76, No. 5, 2006, pp. 405-408. doi:10.1111/j.0902-4441.2005.t01-1-EJH2462.x

[17] G. Damaj, M. Mohty, N. Vey, E. Dincan, R. Bouabdallah, 
C. Faucher, A. M. Stoppa and J. A. Gastaut, "Features of Extramedullary and Extraosseous Multiple Myeloma: A Report of 19 Patients from a Single Center," European Journal of Haematology, Vol. 73, No. 6, 2004, pp. 402406. doi:10.1111/j.1600-0609.2004.00331.x

[18] M. Dimopoulos, A. Spencer, M. Attal, H. M. Prince, J. L. Harousseau, A. Dmoszynska, J. San Miguel, A. Hellmann, T. Facon, R. Foa, A. Corso, Z. Masliak, M. Olesnyckyj, Z. Yu, J. Patin, J. B. Zeldis and R. D. Knight, "Lenalidomide plus Dexamethasone for Relapsed or Refractory Multiple Myeloma," The New England Journal of Medicine, Vol. 357, No. 21, 2007, pp. 2123-2132. doi:10.1056/NEJMoa070594

[19] M. A. Dimopoulos, E. Kastritis, D. Christoulas, M. Migkou, M. Gavriatopoulou, M. Gkotzamanidou, M. Iakovaki, C. Matsouka, D. Mparmparoussi, M. Roussou, E. Efstathiou and E. Terpos, "Treatment of Patients with Relapsed/Refractory Multiple Myeloma with Lenalidomide And Dexamethasone with or without Bortezomib: Prospective Evaluation of the Impact of Cytogenetic Abnormalities and of Previous Therapies," Leukemia: Official Journal of the Leukemia Society of America, Vol. 24, No. 10, 2010, pp. 1769-1778. doi:10.1038/leu.2010.175

[20] E. Kneppers, H. M. Lokhorst, C. M. Eeltink, G. Huls, M. J. Kersten, J. Koedam, M. C. Minnema, M. H. van Oers, R. A. Raymakers, M. R. Schaafsma, E. Vellenga, P. W. Wijermans, S. Wittebol, P. Sonneveld and S. Zweegman, "Analysis of Efficacy and Prognostic Factors of Lenalidomide Treatment as Part of a Dutch Compassionate Use Program," Clinical lymphoma, Myeloma \& Leukemia, Vol. 10, No. 2, 2010, pp. 138-143. doi:10.3816/CLML.2010.n.020

[21] S. Rosenberg, N. Shapur, O. Gofrit and R. Or, "Plasmacytoma of the Testis in a Patient with Previous Multiple Myeloma: Is the Testis a Sanctuary Site?” Journal of Clinical Oncology: Official Journal of the American So- ciety of Clinical Oncology, Vol. 28, No. 27, 2010, pp. e456-e458.

[22] J. M. Calvo-Villas, A. Alegre, C. Calle, M. T. Hernandez, R. Garcia-Sanchez and G. Ramirez, "Lenalidomide Is Effective for Extramedullary Disease in Relapsed or Refractory Multiple Myeloma,” European Journal of Haematology, Vol. 87, No. 3, 2011, pp. 281-284. doi:10.1111/j.1600-0609.2011.01644.x

[23] T. Fukushima, T. Nakamura, H. Iwao and H. Umehara, "Rapid Response of Plasmacytomas to Lenalidomide plus Low-Dose Dexamethasone Therapy in a Patient with Relapsed Multiple Myeloma," American Journal of Hematology, Vol. 86, No. 10, 2011, p. 893. doi:10.1002/ajh.22110

[24] S. Kumar, R. Fonseca, A. Dispenzieri, M. Q. Lacy, J. A Lust, L. Wellik, T. E. Witzig, M. A. Gertz, R. A. Kyle, P. R. Greipp and S. V. Rajkumar, "Prognostic Value of Angiogenesis in Solitary Bone Plasmacytoma,” Blood, Vol. 101, No. 5, 2003, pp. 1715-1717. doi:10.1182/blood-2002-08-2441

[25] J. Adams, V. J. Palombella, E. A. Sausville, J. Johnson, A. Destree, D. D. Lazarus, J. Maas, C. S. Pien, S. Prakash and P. J. Ellott, "Proteasome Inhibitors: A Novel Class of Potent and Effective Antitumor Agents," Cancer Research, Vol. 59, No. 11, 1999, pp. 2615-2622.

[26] A. Palumbo, F. Gay, P. Falco, C. Crippa, V. Montefusco, F. Patriarca, F. Rossini, S. Caltagirone, G. Benevolo, N. Pescosta, T. Guglielmelli, S. Bringhen, M. Offidani, N. Giuliani, M. T. Petrucci, P. Musto, A. M. Liberati, G. Rossi, P. Corradini and M. Boccadoro, "Bortezomib as Induction before Autologous Transplantation, Followed by Lenalidomide as Consolidation-Maintenance in Untreated Multiple Myeloma Patients," Journal of Clinical Oncology, Vol. 28, No. 5, 2010, pp. 800-807. doi:10.1200/JCO.2009.22.7561 